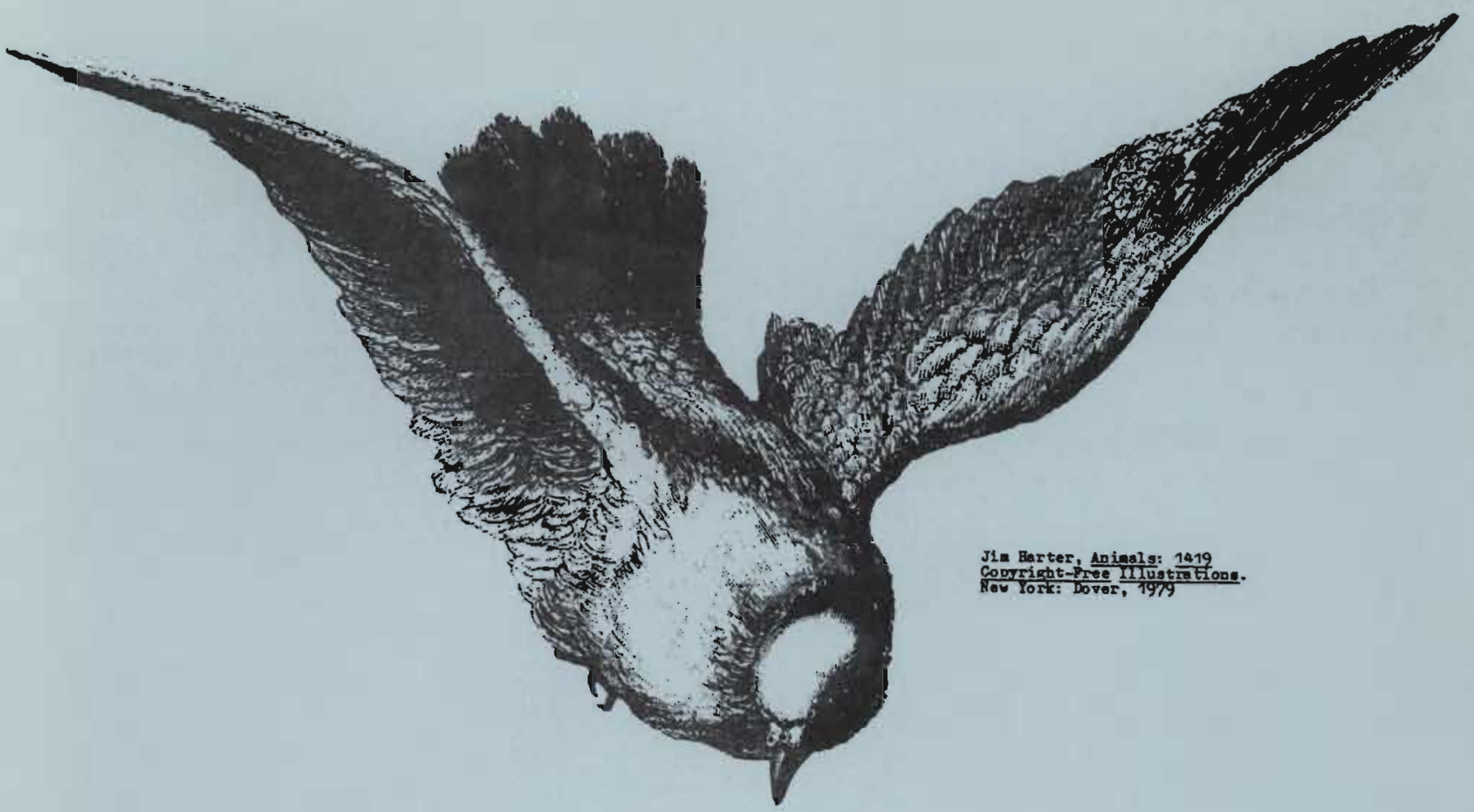

\title{
KIND HEARTS AND BLIND SPOTS
}

Mrs. Roosevelt, I do wonder.

About that silver fox.

You were so perfect, kind and good,

But somehow about wild creatures

You never quite understood.

But I believe if you had listened with

Your gentle heart,

As you did for blacks, children and

Other victims of custom,

That neckpiece you would have jettisoned.

Little foxes and others would have had a

Fresh starc-

A life of freedom; better yet, left unborn

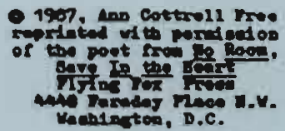

If their sad fate

Was to adorn

Another First Lady, housewife, T.V.-movie star.

Those strangely blind

To what happens afar .... .

\section{Ann Cottrell Free}

